Roland A. Ammann
Leila Baumgartner

\section{Bad news in oncology: which are the right words?}

Received: 31 August 2004

Accepted: 7 September 2004

Published online: 28 January 2005

(C) Springer-Verlag 2005
R. A. Ammann $(\bowtie) \cdot$ L. Baumgartner Division of Pediatric Hematology and Oncology, University Children's Hospital, University of Bern, Inselspital,

CH-3010 Bern, Switzerland e-mail: roland.ammann@insel.ch Tel.: +41-31-6329372

Fax: +41-31-6329507
Communicating good news is usually easy. Communicating bad news is difficult. And communicating very bad news - is part of the "daily routine" work of every oncologist. But it is not routine work at all, and it definitely is difficult, and more than that. The ancient custom to kill the person who communicates the bad news has subsided, admittedly. But it is still a part of our work which we sometimes fear, and which can leave us frustrated and feeling quite helpless. On the one hand it is known that the information we give is an important part of the treatment itself, with effects at least on quality of life [5], while on the other hand evidence suggests that we do not do a particularly good job in giving it [8]. If only we knew which are the right words for these situations, e.g., the disclosure of diagnosis of malignancy, of metastatic disease [2], of relapse, or of life-threatening complications, be it to the patient himself, or to the parents in the case of children with cancer.

In this issue of Supportive Care in Cancer, Scrimin et al. [7] report the results of a practical first step on the way towards a scientific approach to the art of communication in the field of pediatric oncology. Since their work focused on communication with parents of children diagnosed with acute leukemia, most of its messages are directly applicable in the field of adult oncology as well.

The psychology of communication has been a well-established discipline of scientific research for decades [9]. Flammer [3], for example, even discusses explicitly how to communicate bad news. He suggests introducing the matter to be discussed very briefly, then to communicate the bad news in a short, straightforward fashion without attempting to whitewash news that is black [2], and then to be ready and have time to support the recipient(s) of the bad news during the process of digesting the feelings released. There are many communication courses for people working in the health sector [8]. But since communication is, and will always be, art in part and science in part, the recommendations as to how to communicate bad news given in different courses partially contradict each other.

Scrimin et al. aim to shift the balance of science vs art in communication in the direction of science. The aim of their work is not to establish a new concept, but to provide one of many possible starting points for further research in this context. They themselves declare their work to be a preliminary study exploring the fea- 
sibility of the approach as such. By breaking down conversations between a psychologist and parents of children newly diagnosed with cancer into single speech acts, their study addresses the question as to whether the parents are still sensitive to subtle conversational tools - the answer is, fortunately, yes - and seeks to identify the conversational devices to which they respond. The researchers give illustrative examples of speech act categories both of interviewers and parents, enabling non-psychologists also to understand the methodology. They work out the results nicely and in an instructive way, and they end up with a set of suggestions for the clinician. Fortunately, these empirically supported suggestions are not brand new ones. So we do not have to forget everything we know, and learn communication from scratch again.

Of course, a study comparable to a pilot trial will not give definite answers, but the work by Scrimin et al. achieves its aim. It opens the way (1) to future more in-depth research, where issues such as individual differences and the influence of psychosocial and cultural factors are currently addressed in an extension of the study reported; (2) to extensions of the approach to communication with other persons involved such as the child concerned himself, and other important persons in the environment; and (3) to integration of this approach based on the verbal aspects of communication with research on other aspects of communication. These include first paraverbal aspects such as volume, pitch, rate, rhythm and contour of speech, which form a universally recognized system of nonverbal vocal aspects that let people comprehend the emotions of their communication partners even when not understanding a single word of what is actually said $[4,6]$. Second, there is the aspect of nonverbal or "bodily" communication [1], comprising gestures, posture, movements, and mimics. Combining these aspects, there is a wide field open for research, not for the sake of research itself, but for the sake of supporting us in the "how to" of communicating news, which is often bad news.

\section{References}

1. Argyle M (1975) Bodily communication. Methuen, London

2. Butow PN, Dowsett S, Hagerty R, Tattersall MH (2002) Communicating prognosis to patients with metastatic disease: what do they really want to know? Support Care Cancer 10:161168

3. Flammer A (1997) Einführung in die Gesprächspsychologie [Introduction to the psychology of conversation]. Huber, Bern
4. Frick RW (1985) Communicating emotion. The role of prosodic features. Psychol Bull 97:412-429

5. Kim Y, Roscoe JA, Morrow GR (2002) The effects of information and negative affect on severity of side effects from radiation therapy for prostate cancer. Support Care Cancer 10:416-421

6. Scherer KR (1979) Nonlinguistic vocal indicators of emotion and psychopathology. In: Izard CE (eds) Emotions in personality and psychopathology. Plenum, New York
7. Scrimin S, Axia G, Tremolada M, Pillon M, Capello F, Zanesco L (2005) Conversational strategies with parents of newly diagnosed leukemic children. An analysis of 4880 conversational turns. Support Care Cancer (this issue)

8. Tiernan E (2003) Communication training for professionals. Support Care Cancer 11:758-762

9. Watzlavick P, Beavin JH, Jackson DD (1967) Pragmatics of human communication. Norton, New York 